\title{
Rational design, supramolecular synthesis and solid state characterization of two bicomponent solid forms of Mebendazole
}

Received 00th January 20xx, Accepted 00th January 20xx

DOI: $10.1039 / x 0 x \times 00000 x$

\author{
Eduardo L. Gutiérrez ${ }^{1}$, Agustín A. Godoy ${ }^{2}$, Griselda E. Narda ${ }^{2}$ and Javier Ellena ${ }^{3 *}$
}

\section{Introduction}

Mebendazole (MBZ, methyl N-(5-benzoylbenzimidazol-2-yl) carbamate, Scheme 1) is a broad-spectrum benzimidazolederivate anthelmintic and postulated as a possible antitumor drug. ${ }^{1}$ It is a Class II drug of the Biopharmaceutical Classification System ${ }^{2}$ due to its poor solubility either in water or $0.1 \mathrm{~mol} \mathrm{~L}^{-1} \mathrm{HCl}(\mathrm{aq})$ but high permeability ${ }^{3}$ and it is included in the World Health Organization (WHO) Model List of Essential Drugs ${ }^{4}$. This active pharmaceutical ingredient (API) presents three polymorphs named as A, B and C that exhibit marked differences in their physicochemical properties and bioavailability. ${ }^{5} \mathrm{MBZ} A$ is the least water soluble form being MBZ $B$ the most soluble one, while MBZ $C$ presents an intermediate solubility value $(9.84 \pm 0.05,71.3 \pm 0.5$ and $35.4 \pm$ $0.5 \mathrm{mg} \mathrm{L}^{-1}$ respectively in pure water). This last one solid form is the therapeutically preferred one to treat several parasite infections (ascariasis, uncinariasis, oxyuriasis, and trichuriasis) $)^{6-8}$. Such is the importance of the polymorph choice that the International Pharmacopoeia $5^{\text {th }}$ Edition restricts the suitable polymorphic form to $\mathrm{MBZ} C$ in chewing tablets, emphasizing that the overall manufacturing process

${ }^{1}$ INQUISAL-CONICET, San Luis, Argentina - Área de Química Física, Facultad de Química, Bioquímica y Farmacia, Universidad Nacional de San Luis. Chacabuco y Pedernera 5700, San Luis, Argentina.

${ }^{2}$ Instituto de Investigaciones en Tecnología Química (INTEQUI), Almte. Brown 1500-1402, D5700APA, San Luis - Área de Química General e Inorgánica “Dr. G. F. Puelles", Facultad de Química, Bioquímica y Farmacia, Universidad Nacional de San Luis, Chacabuco y Pedernera, 5700 San Luis, Argentina.

${ }^{3}$ Instituto de Física de São Carlos, Universidade de São Paulo, CP 369, 13.560-970, São Carlos, SP, Brazil.

*e-mail address: javiere@ifsc.usp.br

Electronic Supplementary Information (ESI) available: [details of any supplementary information available should be included here]. See DOI: $10.1039 / x 0 \times x 00000 x$ should be designed and controlled to minimize its conversion into the more stable polymorph $A^{8,9}$<smiles>COC(=O)[NH+]c1n[nH]c2cc(C(=O)c3ccccc3)ccc12</smiles>

methyl $N$-(5-benzoyl-1H-benzimidazol-2-yl) carbamate<smiles>COC(=O)Nc1nc2ccc(C(=O)c3ccccc3)cc2[nH]1</smiles>

methyl $N$-(5-benzoyl-3H-benzimidazol-2-yl) carbamate

Scheme 1. Above: the $1 \mathrm{H}$-tautomer of MBZ found in polymorph $\mathrm{C}$ Below: The $3 \mathrm{H}$-tautomer found in MBZ A.

MBZ presents enamine-imino tautomerism in solution. ${ }^{10}$ As stated by Agatonovic-Kustrin et al. $^{8}$, tautomerism is responsible for MBZ polymorphism. The $1 \mathrm{H}$-tautomer shown in Scheme 1 (above) is the only one present in MBZ polymorph $C$, while MBZ polymorph $A$ is formed by the crystallization of the $3 \mathrm{H}$-tautomer shown in Scheme 1 (below). The crystal structure of polymorphs $A$ and $C$ have been previously 
reported $^{11,12}$, while the structure of polymorph $B$ remains undetermined. These three polymorphs show differences in their physicochemical and mechanical properties, which are related to numerous other pharmaceutical interesting properties (drug dissolution, absorption and bioavailability, but also manufacturing reproducibility, stability in storage and transport, etc.). De Villiers et al. have studied the thermal stability of MBZ polymorphs. ${ }^{13}$ They characterized the firstorder phase transition from polymorph $C$ to $A$ at approx. 200 ${ }^{\circ} \mathrm{C}$ and found evidence of a similar transformation from MBZ $\mathrm{B}$ into MBZ A. It have been recently reported that the MBZ most stable form $A$ does not melt but rather decomposes above its thermal stability of approx. $200{ }^{\circ} \mathrm{C} .{ }^{14,15}$

Regarding the relationship between the physicochemical properties and pharmaceutical performance, on one hand due to its high stability and therefore extremely low water solubility, therapeutic assays suggest that MBZ A has similar efficacy to placebos in controlling worm infections. On the other hand, the most soluble and least stable polymorph B has shown to be more toxic during both anthelmintic and anticancer tests. ${ }^{16} \mathrm{MBZ} \mathrm{C}$ falls right into the therapeutic window, since its dissolution profile and its solubility ensure acceptable efficacy, meanwhile concentration values that can cause toxicity are not reached. However, polymorph interconversion has been demonstrated to occur in tablets prepared with form $\mathrm{C}$, which suffer a transformation to products containing form $A$ under the effects of moisture and heat. Due to the same phenomenon, suspensions of polymorph C may also contain part of their active principle converted to polymorph $A .^{17}$ This polymorph interconversion in solid drug formulations is a big problem for the pharmaceutical industry.

In this work, we developed two novel bicomponent solid forms of MBZ aiming to increase the knowledge about its intermolecular interactions as a mean to explore the possible ways to modulate properties such as solubility and thermal stability and to avoid polymorph interconversion. The design and synthesis of multicomponent systems using crystalengineering techniques is a strategy widely used to improve the performance and processability of Active Pharmaceutical Ingredients (APIs). This approach has been also used to modulate the pharmacokinetic properties of the API solid form since it does not modify the intrinsic chemical structure of the drug but only its supramolecular environment. ${ }^{18,19}$

Here we use methylsulfuric $\left(\mathrm{HSO}_{4} \mathrm{CH}_{3}\right)$ and perchloric $\left(\mathrm{HClO}_{4}\right)$ acids as coformers. $\mathrm{HSO}_{4} \mathrm{CH}_{3}$ is used as counterion in some drug formulations registered in the FDA Orange Book $40^{\text {th }}$ Edition. ${ }^{20}$ In contrast, there is not much literature about multicomponent drug crystals incorporating perchloric acid and. ${ }^{21}$ Since sulfur and chlorine present similar size, $\mathrm{HClO}_{4}$ was chosen as a $\mathrm{HSO}_{4} \mathrm{CH}_{3}$ analogue in an attempt to evaluate the effect in the crystal packing of the presence/absence of methyl group in the coformer. Both systems were designed based on the statistical probability of formation of a supramolecular heterosynthon of the $R_{2}^{2}(8)$ type $^{22}$ between the MBZ molecule and the appropriate coformers instead of the highly stable

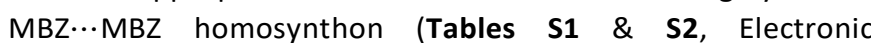

Supplementary Information -ESI-). As shown in Scheme 1 (above), MBZ $\mathbf{1 H}$-tautomer exhibits one polarized $\mathbf{N 1 - H}$ bond that could act as hydrogen-bond (H-bond) donor, and one basic site on $\mathbf{N 2}$ that could act as $\mathrm{H}$-bond acceptor; this particular structure may allow the assembly of one MBZ molecule with a suitable coformer by two complementary intermolecular hydrogen bonds. Another similar $\mathrm{R}_{2}{ }^{2}(8)$ synthon could be designed for the $3 \mathrm{H}$-tautomer (Scheme 1, below) involving $\mathbf{N 3}$ as $\mathbf{H}$-bond acceptor and $\mathbf{N 1 - H}$ as $\mathrm{H}$-bond donor. In the Tables S3 \& S4 we present the $\mathrm{R}_{2}{ }^{2}(8)$ synthons found among the cocrystals and salts reported in the literature ${ }^{23-28}$, including one nitrate salt previously reported by $\mathrm{us}^{29}$. Concerning these specific chosen coformers, we also had to be aware of possible proton transfer, prior to crystallization, and therefore the salification of the API. Drug salts usually tend to convert to the raw APIs. Previous reports show that MBZ salts undergo a solvent-mediated transformation to pure MBZ polymorph $\mathrm{C}^{29,30}$. Here we focus mainly on the description of the crystal structure of these systems, the study of its thermal stability and the corresponding suspension stability of both new solid forms. Hirshfeld surface analysis was performed to complement the atom-by-atom analysis of intermolecular interactions and the relative stability of both compounds. The Hirshfeld surface emerged from an attempt to define the space occupied by a molecule as whole in a crystal for the purpose of partitioning the crystal electron density into molecular fragments. Since this surface is defined by the molecule and the proximity of its nearest neighbours, it encodes information about intermolecular interactions which can be readily identified using the tools provided by Hirshfeld surface analysis. ${ }^{31,32}$

\section{Experimental}

\section{Reagents}

Samples of MBZ (295.29 $\mathrm{g} \mathrm{mol}^{-1}$ ) polymorphs A and C were kindly provided by Laboratorio de Control de Calidad de Medicamentos, UNSL. Purity of these samples was checked using PXRD. Absolute methanol $\left(\mathrm{CH}_{3} \mathrm{OH}\right.$, Sintorgan, analytical grade) was used, without any further purification, as solvent for the suspension and dissolution of the drug. Perchloric acid $\left(70 \% \mathrm{w} / \mathrm{w}, 1.68 \mathrm{~g} \mathrm{~mL}^{-1}\left(20^{\circ} \mathrm{C}\right), 100.46 \mathrm{~g} \mathrm{~mol}^{-1}\right)$ and sulfuric acid $\left(\mathrm{H}_{2} \mathrm{SO}_{4}, 98 \% \mathrm{w} / \mathrm{w}, 1.84 \mathrm{~g} \mathrm{~mL}^{-1},\left(20{ }^{\circ} \mathrm{C}\right), 98.08 \mathrm{~g} \mathrm{~mol}^{-1}\right)$ were obtained from Merck and Tetrahedron, respectively, and used without further purification too. Methylsulfuric acid (also known as methyl bisulfate due to its monoprotic nature, $112.10 \mathrm{~g} \mathrm{~mol}^{-1}$ ) was synthesized by direct esterification of $\mathrm{H}_{2} \mathrm{SO}_{4}$ with $\mathrm{CH}_{3} \mathrm{OH}^{33,34}$. The reaction was carried out by slowly mixing $1 \mathrm{~mL} \mathrm{H}_{2} \mathrm{SO}_{4} 98 \% \mathrm{w} / \mathrm{w}$ with $9 \mathrm{~mL}$ of absolute $\mathrm{CH}_{3} \mathrm{OH}$ in an open vessel at room temperature (approx. 22-25 ${ }^{\circ} \mathrm{C}$ ) (Caution: very exothermic reaction). Esterification was verified using UV-Vis spectroscopy.

\section{Supramolecular synthesis}

A sample of MBZ polymorphs $A$ or $C$ of approx. $25 \mathrm{mg}(0.10$ mmol) was suspended in $10 \mathrm{~mL}$ of absolute $\mathrm{CH}_{3} \mathrm{OH}$ at room 
temperature with constant magnetic stirring (500 rpm), $50 \mu \mathrm{L}$ of acid solution $\left(\mathrm{HClO}_{4}\right.$ : $0.60 \mathrm{mmol}$ and $\mathrm{HSO}_{4} \mathrm{CH}_{3} 0.10 \mathrm{mmol}$ ) were added to achieve complete dissolution of the solid. After 10 min stirring, the solution was filtered. Finally, the solution was brought to $5{ }^{\circ} \mathrm{C}$ to achieve slow evaporation of the solvent. After approx. seven days, the formation of small, prismatic crystals was observed. These crystals were separated by filtration and washed several times with $n$-hexane. Powder $\mathrm{X}$-ray diffraction and FT-IR spectroscopy were used to check the purity and identity of the solids, which were then kept at room temperature for further characterizations.

As mentioned before, it is important to be aware about the possible salification of the API. The empirical " $p K_{a}$ Rule" states that salt should be expected when the difference in $\mathrm{pK}_{\mathrm{a}}$ between the conjugated acid of the base and the acid is greater that approx. 2-3 units. Considering the values of $\mathrm{pK}_{\mathrm{a}}$ of $\mathrm{MBZ}$ conjugated acid $\left(\mathrm{HMBZ}^{+}, 4,43^{35}\right)$ and those of $\mathrm{HClO}_{4}(-10)$ and $\mathrm{HSO}_{4} \mathrm{CH}_{3}(-2.6)$, a proton transfer prior to crystallization is very likely $\left(\Delta \mathrm{pK}_{\mathrm{a}, 1}=14.43\right.$ and $\left.\Delta \mathrm{pK}_{\mathrm{a}, 2}=7.03\right)$ which need to be confirmed by SCXRD.

\section{Powder X-ray diffraction}

Powder X-ray diffraction (PXRD) analysis was performed on a Rigaku Ultima IV diffractometer (Rigaku Corporation) using $\mathrm{Cu} \mathrm{K} \alpha$ radiation, in a step mode, between $3-50^{\circ}$ in $2 \theta$ with a scanning rate of $0.6^{\circ} \mathrm{min}^{-1}$ ( $2 \mathrm{~s}$ per step) and a step of $0.02^{\circ}$. The powder diffraction patterns were collected and processed with «SmartLab Studio-II» software, associated with the diffractometer.

\section{FT-IR Spectroscopy}

Fourier transformed infrared spectrum were recorded on a Nicolet Protègè 460 spectrophotometer (Nicolet Instrument Corporation) provided with a Csl beamsplitter, in the 4000-400 $\mathrm{cm}^{-1}$ range with 64 scans and spectral resolution of $4 \mathrm{~cm}^{-1}$, using the $\mathrm{KBr}$ pellet technique. Measures were collected and processed with the software "Omnic», associated to the spectrometer. The spectra at controlled increasing temperatures were obtained by placing the pellet in a variabletemperature homemade cell in the $25^{\circ} \mathrm{C}-250{ }^{\circ} \mathrm{C}$ range within air atmosphere.

\section{Single-crystal X-ray diffraction}

Suitable-sized clear crystals were selected for the single crystal X-ray diffraction experiments. The data were collected at room temperature $(293(2) \quad K)$ on a Bruker APEX-II diffractometer with $C C D$ detector system equipped with a Mo source $(\lambda=0.71073 \AA)$. Data integration, cell determination and final parameters were obtained using the software Bruker SAINT ${ }^{36}$ included in APEX $2^{37}$ software suite. The structures were solved by direct methods through the program SHELXLT' and the model obtained was refined by full matrix least squares on F2 using the program SHELXLT ${ }^{38}$, included in Olex $2^{39}$ software. All the hydrogen atoms were placed in calculated positions and refined with fixed individual displacement parameters $\left[\mathrm{U}_{\text {iso }}(\mathrm{H})=1.2 \mathrm{U}_{\text {eq }}\right.$ or $\left.1.5 \mathrm{U}_{\mathrm{eq}}\right]$ according to the riding model. The crystallographic information files (CIFs) were deposited in the Cambridge Structural Data Base ${ }^{40}$ under the codes CCDC 1995782 and 1995783. Copies of the data can be obtained, free of charge, via www.ccdc.cam.ac.uk. Geometrical calculation, molecular representations, pictures and tables were performed by and/or generated with the MERCURY 4.3.1 ${ }^{41}$, PLATON $^{42}$ and PARST softwares, these last two incorporated in the WINGX 2020.1 suite $^{43}$.

\section{Hirshfeld surface analysis}

Hirshfeld surface analysis was performed using the software CrystalExplorer $17^{44}$ using the $\mathrm{CIFs}$ as input files. Hirshfeld surfaces for $\mathrm{MBZH} \cdot \mathrm{ClO}_{4}$ and $\mathrm{MBZH} \cdot \mathrm{SO}_{4} \mathrm{CH}_{3}$ were mapped with $d_{\text {norm }}$ over the range -0.35 to 1.25 . Shape index and curvedness surfaces were mapped over the ranges -1.0 to 1.0 and -4.0 and 0.4 respectively. $2 \mathrm{D}$-fingerprints plots were obtained for de $y$ di between 0.4 and 2.6 .

\section{Thermal analysis}

Thermogravimetric analysis (TGA) and differential thermal analysis (DTA) measures were obtained simultaneously with a Shimadzu DTG-60 instrument (Shimadzu Inc.), using platinum pan, flowing air at $20 \mathrm{~mL} \mathrm{~min}{ }^{-1}$, and a heating rate of $10^{\circ} \mathrm{C}$ $\mathrm{min}^{-1}$ from room temperature (RT) to $600{ }^{\circ} \mathrm{C}$. TGA and DTA curves were collected and processed with "TA60" software, associated to the analyser.

\section{UV-visible spectroscopy, solubility and stabilities studies}

UV-visible absorbance measures were carried out in an Agilent 8454 UV-vis spectrophotometer (Agilent Technologies), collected and processed with «8453 UV Visible Chem station Rev.A.10.01" software associated to the instrument.

Equilibrium solubility of $\mathrm{MBZH} \cdot \mathrm{ClO}_{4}$ at room temperature was evaluated and compared against those of mebendazole polymorphs $\mathrm{A}$ and $\mathrm{C}$ in $0.1 \mathrm{~mol} \mathrm{~L}^{-1}$ hydrochloric acid solution, using the shake flask saturation method ${ }^{45}$. Saturated solutions of the three solids were prepared by stirring an excess amount of the solids into $4 \mathrm{~mL}$ of the dissolution medium for a period of $48 \mathrm{hs}\left(20{ }^{\circ} \mathrm{C}\right.$ and $\left.200 \mathrm{rpm}\right)$ in a SI-300R shaker (Lab Companion). After sedimentation, the solutions were filtered through a $0.45 \mathrm{~mm}$ filter (Exacta). The identity of the solid sediments was checked by PXRD. UV-Vis spectroscopy was employed to measure $M B Z$ concentration in the saturated solutions, applying a direct calibration method, using the absorbance maxima as a parameter proportional to the concentration. Saturated solutions were diluted in the dissolution medium to ensure working on the spectrophotometer linear range of response.

\section{Results and discussion}

Crystalline habit, identity and purity 
$\mathrm{MBZH} \cdot \mathrm{ClO}_{4}$ crystallize as yellowish/brownish small prismatic crystals, while $\mathrm{MBZH} \cdot \mathrm{SO}_{4} \mathrm{CH}_{3}$ crystallizes as elongated prismatic colorless crystals in the shape of needles (Figure S1, ESI).

Preliminary evidence about the identity of presumably new solid products was provided by their vibrational spectra and their powder X-ray diffractions patterns. These measures were performed prior to the single-crystal X-ray diffraction experiments. Ayala et al. $^{46}$ have established that the position of the band corresponding to the carbamate carbonyl stretching mode could fingerprints the crystalline forms of MBZ. This band appears at $1730 \mathrm{~cm}^{-1}, 1715 \mathrm{~cm}^{-1}$ and $1697 \mathrm{~cm}^{-}$

${ }^{1}$ for polymorphs $\mathrm{A}, \mathrm{C}$ and $\mathrm{B}$, respectively 14 , and at $1759 \mathrm{~cm}^{-1}$ and $1757 \mathrm{~cm}^{-1}$ in the $\mathrm{MBZH} \cdot \mathrm{ClO}_{4}$ and $\mathrm{MBZH} \cdot \mathrm{SO}_{4} \mathrm{CH}_{3}$ spectra, respectively. Further evidence of the inclusion of the anions in the crystal structure was given by the identification of other bands. The bands assigned to the $v_{3}$ and $v_{4}$ modes of the perchlorate anion appears at $1115 \mathrm{~cm}^{-1}$ and $625 \mathrm{~cm}^{-1}$, and the bands of the same modes of methylsulfate anion were found at $1113 \mathrm{~cm}^{-1}$ and $614 \mathrm{~cm}^{-1}$. The bands corresponding to stretching modes of the methyl group of the anion appears at $2850 \mathrm{~cm}^{-1}$ and $2815 \mathrm{~cm}^{-1}$, while the stretching modes of the methyl group of the carbamate moiety of MBZ are at $2955 \mathrm{~cm}^{-}$ ${ }^{1}$ and $2917 \mathrm{~cm}^{-1}$. IR spectra are shown in Figure $\mathbf{S 2}$.

The same solid $\mathrm{MBZH} \cdot \mathrm{ClO}_{4}$ form was obtained from both MBZ A and MBZ C polymorph, while the solid $\mathrm{MBZH} \cdot \mathrm{SO}_{4} \mathrm{CH}_{3}$ was obtained just from MBZ C (synthesis from MBZ A was not tested). We compared the powder $X$-ray diffractions patterns of both solids with those calculated for MBZ A and MBZ C, and the experimental one of MBZ B previously reported ${ }^{24,47}$ (Figure 1). This comparison ruled out the formation of any of the three polymorphs after solvent evaporation as a sub-product, since none of their characteristic peaks were observed in the experimental patterns of $\mathrm{MBZH} \cdot \mathrm{ClO}_{4}$ and $\mathrm{MBZH} \cdot \mathrm{SO}_{4} \mathrm{CH}_{3}$. With these evidences, we performed the SC-XRD experiments.

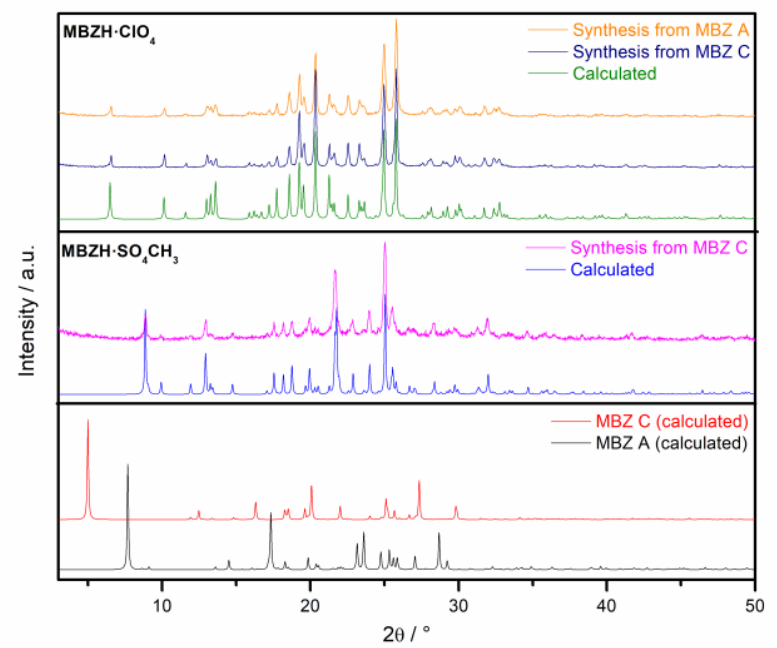

Figure 1. Experimental Powder X-ray diffractions patters of MBZ perchlorate and MBZ methyl sulfate compared with those calculated from solved structures.
PXRD pattern and FT-IR spectra analysis showed that both compounds, kept at room temperature, were stable in the solid state for at least for one year after the synthesis, and no evidence of the formation of any MBZ polymorph was found (Figure S3).

\section{Structural description}

Single-crystal X-ray diffraction experiments confirmed the formation of two new solids, mebendazole perchlorate $\left(\mathrm{MBZH} \cdot \mathrm{ClO}_{4}\right)$ and mebendazole methylsulfate $\left(\mathrm{MBZH} \cdot \mathrm{SO}_{4} \mathrm{CH}_{3}\right)$. Both solids are ionic with a 1:1 stoichiometry.

Mebendazole perchlorate salt. This salt crystallizes in the monoclinic $\mathrm{P} 2_{1} / \mathrm{n}$ (14) space group. Crystal data, data collection and structure refinement parameters are shown in Table 1.

The crystal structure shows the total proton transfer from the perchloric acid to the $\mathbf{N} \mathbf{2}$ of the imidazole ring of the drug, resulting in an ionic solid. An ORTEP type view of the asymmetric unit of $\mathrm{MBZH} \cdot \mathrm{ClO}_{4}$, displaying the atoms labelling and the $50 \%$ probability ellipsoids, is shown in Figure 2.A.
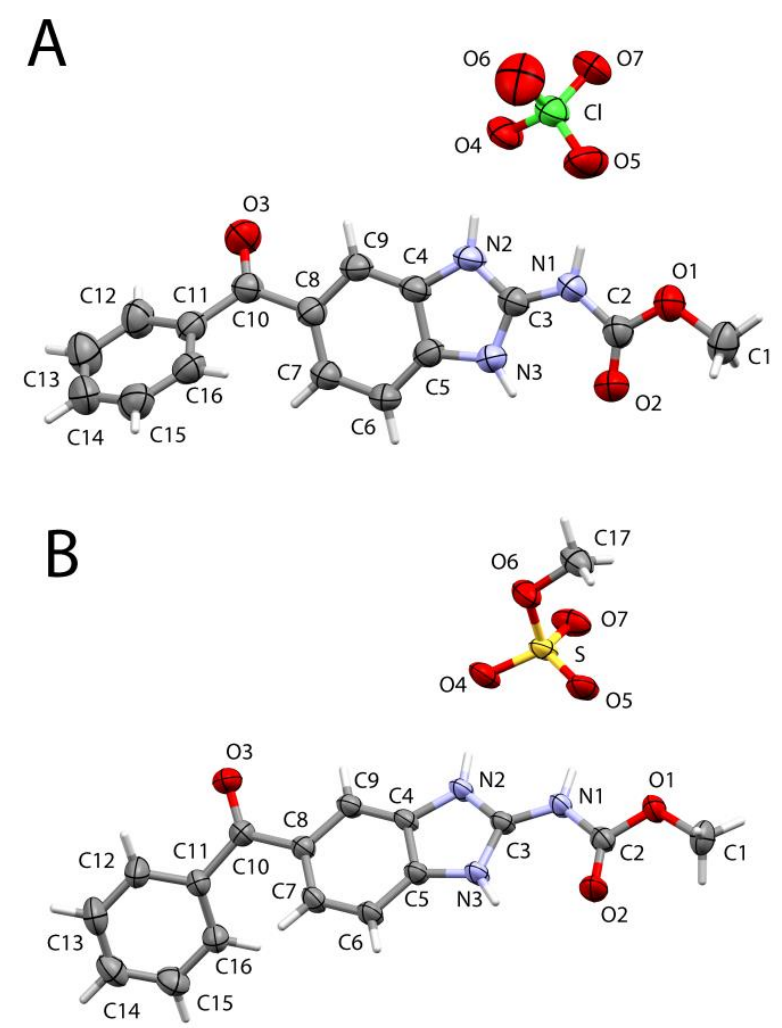

Figure 2. View of MBZ perchlorate (A) and MBZ methylsulfate (B) asymmetric units, showing the atoms labelling and the $50 \%$ probability ellipsoids for non-hydrogen atoms. The hydrogen atoms are shown as sticks of arbitrary radii. (Color code. C: grey; H: white; O: red; N: blue; $\mathrm{Cl}$ : green; S: yellow.) 
Table 1. Crystal data, data collection and structure refinement parameters of MBZ perchlorate and MBZ methylsulfate.

Table 1

\begin{tabular}{|c|c|c|}
\hline Identification code & $\mathrm{MBZ}$ perchlorate $\left(\mathrm{MBZH} \cdot \mathrm{ClO}_{4}\right)$ & $\mathrm{MBZ}$ methylsulfate $\left(\mathrm{MBZH} \cdot \mathrm{SO}_{4} \mathrm{CH}_{3}\right)$ \\
\hline Empirical formula & $\mathrm{C}_{16} \mathrm{H}_{14} \mathrm{ClN}_{3} \mathrm{O}_{7}$ & $\mathrm{C}_{17} \mathrm{H}_{17} \mathrm{~N}_{3} \mathrm{O}_{7} \mathrm{~S}$ \\
\hline Formula weight & 395.75 & 407.39 \\
\hline Temperature / $\mathrm{K}$ & $293(2)$ & $293(2)$ \\
\hline Crystal system & monoclinic & triclinic \\
\hline Space group & $\mathrm{P} 2_{1} / \mathrm{n}(14)$ & $\mathrm{P}-1(2)$ \\
\hline$a / \AA$ & $6.7934(7)$ & $9.1092(11)$ \\
\hline$b / \AA$ & $9.2159(14)$ & $9.9717(14)$ \\
\hline$c / \AA$ & $27.264(5)$ & $9.9908(14)$ \\
\hline$\alpha /{ }^{\circ}$ & 90 & $92.075(12)$ \\
\hline$\beta /{ }^{\circ}$ & $93.007(12)$ & $102.401(11)$ \\
\hline$\gamma /{ }^{\circ}$ & 90 & $90.209(10)$ \\
\hline Volume / $\AA^{3}$ & $1704.5(4)$ & $888.7(2)$ \\
\hline $\mathrm{Z} / \mathrm{Z}^{\prime}$ & 4 & 2 \\
\hline$\rho_{\text {calc }} / \mathrm{g} / \mathrm{cm}^{3}$ & 1.542 & 1.528 \\
\hline$\mu / \mathrm{mm}^{-1}$ & 0.27 & 0.23 \\
\hline$F(000)$ & 816 & 424 \\
\hline Crystal size $/ \mathrm{mm}^{3}$ & $0.25 \times 0.18 \times 0.15$ & $0.16 \times 0.05 \times 0.02$ \\
\hline Radiation & $\operatorname{MoK} \alpha(\lambda=0.71073)$ & $\operatorname{MoK} \alpha(\lambda=0.71073)$ \\
\hline $2 \Theta$ range for data collection $/{ }^{\circ}$ & 5.338 to 68.86 & 5.469 to 69.066 \\
\hline Index & $-10 \leq h \leq 9,-21 \leq k \leq 14,-40 \leq l \leq 34$ & $-14 \leq h \leq 10,-15 \leq \mathrm{k} \leq 14,-13 \leq \mathrm{l} \leq 35$ \\
\hline Reflections collected & 10221 & 7683 \\
\hline Independent reflections & $6430\left[R_{\text {int }}=0.066, R_{\text {sigma }}=0.144\right]$ & $64296\left[R_{\text {int }}=0.031, R_{\text {sigma }}=0.115\right]$ \\
\hline Data/restraints/parameters & $6430 / 0 / 246$ & $6296 / 0 / 255$ \\
\hline Goodness-of-fit on $F^{2}$ & 1.03 & 1.05 \\
\hline Final $R$ indexes $[I \geq 2 \sigma(I)]$ & $R_{1}=0.092, w R_{2}=0.204$ & $\mathrm{R}_{1}=0.065, \mathrm{wR}_{2}=0.151$ \\
\hline Final $R$ indexes [all data] & $\mathrm{R}_{1}=0.244, \mathrm{wR}_{2}=0.285$ & $\mathrm{R}_{1}=0.164, \mathrm{wR}_{2}=0.188$ \\
\hline Largest diff. peak/hole / e $\AA^{-}$ & $0.54 /-0.34$ & $0.29 /-0.35$ \\
\hline
\end{tabular}

Table 2. Hydrogen-bonding geometry for MBZ perchlorate and MBZ methylsulfate

Table 2

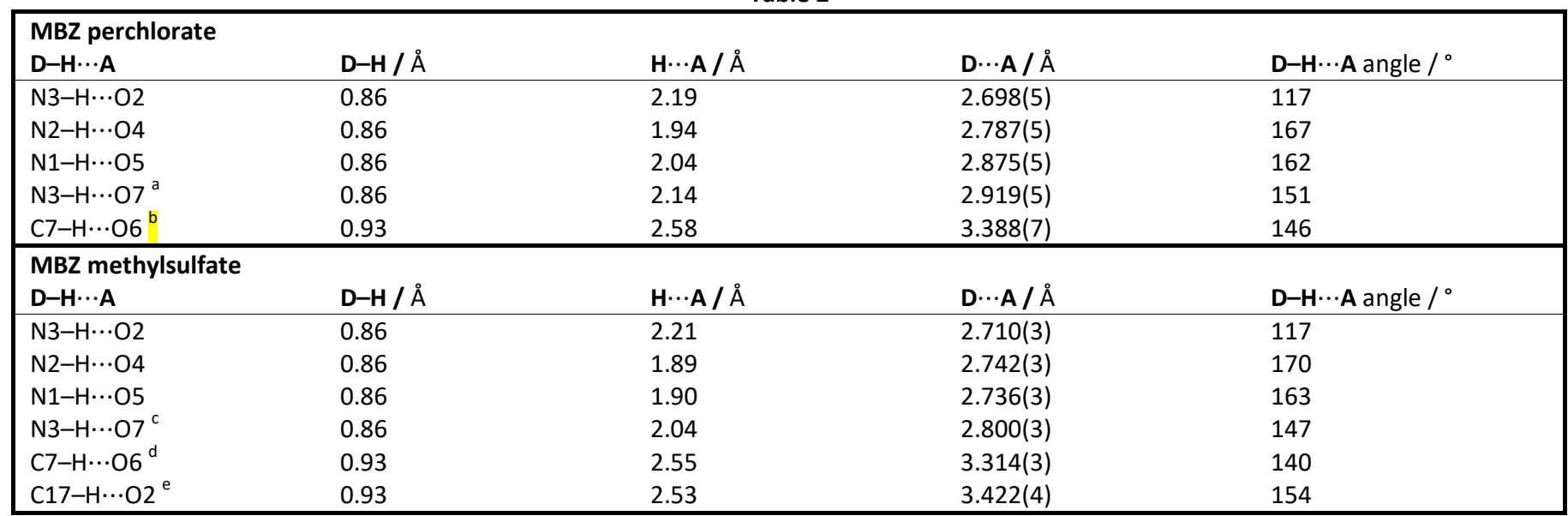

D: donor. A: acceptor

Equivalent positions:
a: $x, y+1, z$
$\mathrm{d}:-\mathrm{x}+1,-\mathrm{y}+1,-\mathrm{z}+1$
b: $x+1, y+1, z$
e: $x+1, y, z$
$c: x-1, y, z$

Protonation causes changes in the bond lengths of the imidazole ring. In the crystal structure of polymorph $\mathrm{C}^{12}$, the length of the amine (N3-C3) and imine (N2-C3) bonds are significantly different: $1.349(9) \AA$ and $1.30(1) \AA$, respectively.
On the other hand, in the $\mathrm{MBZH}^{+}$cation, the bond N2-C3 is $1.337(6) \AA$ and the bond N3-C3 is $1.321(6) \AA$, showing a partial loss of the double bond character due to the presence of a positive charge on N2. This behavior is caused by the displacement of the negative charge on the ring as a 
consequence of protonation. It is also worth noting that protonation shortens the length of the bond $\mathbf{N 1 - C 3}$, due to an additional displacement of electron density from $\mathbf{N} \mathbf{1}$ towards the site of protonation. This bond is 1.37(1) $\AA$ in MBZ C, while it is 1.341(6) $\AA$ in $\mathrm{MBZH}^{+}$, suggesting a higher double bond character (Figure S4). These observations are consistent with the behavior exhibits by protonated MBZ molecule in all reported structures.

In the $\mathrm{MBZH} \cdot \mathrm{ClO}_{4}$ crystal structure the $\mathrm{MBZH}^{+}$cation shows a methylcarbamate group coplanar with the benzimidazole ring, forming an intramolecular resonance-assisted $\mathrm{H}$-bond $(\mathrm{RAHB})^{48}$ between the carbonylic oxygen 02 (acceptor, A) and the imidazolic nitrogen N3 (donor, D; A $\cdots \mathbf{H}: 2.19 \AA$, Table 2). The $\mathrm{MBZH}^{+}$cation also shows a dihedral angle of $51.6(2)^{\circ}$ between the least squares planes determined by the benzimidazolic and benzoyl rings (Figure 3.D).

The asymmetric unit of the solid consists of one $\mathrm{MBZH}^{+}$ cation and one $\mathrm{ClO}^{-}$anion. Both ions form a supramolecular motif of the $\mathrm{R}_{2}{ }^{2}(8)$ type stabilized by two intermolecular $\mathrm{H}$ -

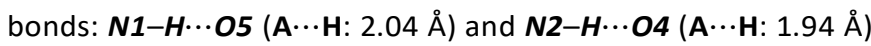
(Figure 3.B). In Table S3 we collected the $\mathrm{H}$-bond distances of all MBZ salts that presents this supramolecular motif (no cocrystals were found exhibiting this synthon). This arrangement is not coplanar: there is a dihedral angle of 23.0(3) $)^{\circ}$ between the planes determined by the atoms N3, C3 and $\mathbf{N 1}$, and the atoms $\mathbf{O 4}, \mathbf{C l}$ and $\mathbf{O 5}$ of the perchlorate anion.

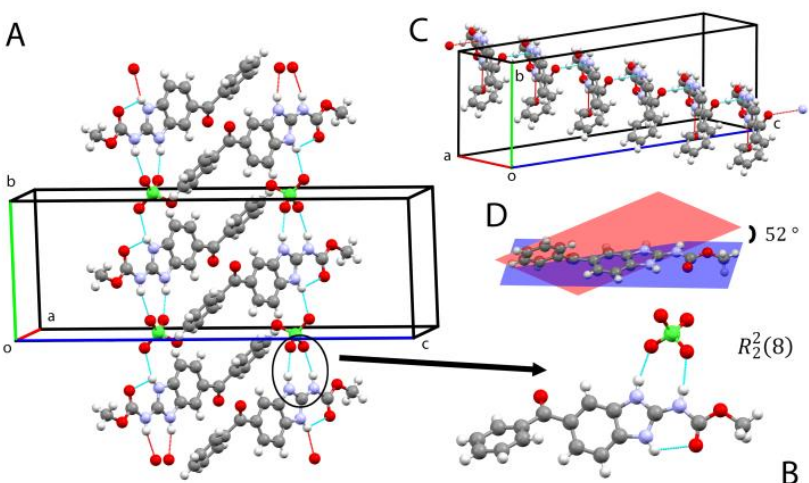

Figure 3.A. Antiparallel chains along $b$ axis of ionic pairs $\mathrm{MBZH}^{+} / \mathrm{ClO}_{4}^{-}$assembled by intermolecular $\mathrm{H}$-bonds.

B. Supramolecular motif $\mathrm{R}_{2}{ }^{2}(8)$ formed by one $\mathrm{MBZH}^{+}$cation and one $\mathrm{ClO}_{4}{ }^{-}$anion. $\mathrm{C}$. Arrangements of $\mathrm{MBZH}^{+}$in the plane ac stabilized by a peculiar benzoyl/imizadole interaction. D. Conformation of $\mathrm{MBZH}^{+}$ cation in the crystalline state. (Color code. $\mathrm{C}$ : grey; $\mathrm{H}$ : white; $\mathrm{O}$ : red; $\mathrm{N}$ : blue; $\mathrm{Cl}$ : green.)

The ionic pairs $\mathrm{MBZH}^{+} / \mathrm{ClO}_{4}{ }^{-}$are connected along the $\boldsymbol{b}$ axis through $\mathrm{H}$-bond interactions between the atom $\mathbf{N 3}$ of one pair and the atom 07 of the next pair $(\mathbf{A} \cdots \mathbf{H}: 2.14 \AA)$. These chains are ordered in an antiparallel way with the ionic $\mathrm{MBZH}^{+} / \mathrm{ClO}_{4}^{-}$ pairs of opposite chains related by an inversion centers (Figure 3.A). In the $a c$ plane, there is a short contact that contributes to crystal packaging, which was not found in others solid forms of the drug: the imidazolic N2 connects with the bezoylic 03 of an adjacent molecule (3.012(5) §̊). This interaction, also revealed by Hirshfeld surface analysis (see below), gives rise to the arrangement of $\mathrm{MBZH}^{+}$shown in Figure 3.C. Numerous other short-contact interactions can be found, which contribute to final stabilization of the crystal packing; among them, the $\mathbf{C 3} \cdots 03$ (2.951(6) $\AA$ ) contact that reinforces the N2 $\cdots \mathbf{O} 3$ interaction. The oxygen atoms of the perchlorate anions, where lies the negative charge of the compound, are involved in various short-range interactions. For instance, the atoms $\mathbf{O 5}$ and $\mathbf{O} \mathbf{7}$ interact with the atoms $\mathbf{C 2}$ and $\mathbf{C 1}$ of the methylester group at the end of a contiguous MBZ molecule in the $a c$ plane

Mebendazole methylsulfate salt. Mebendazole methylsulfate crystallizes in the triclinic P-1 (2) space group. Crystal data, data collection and structure refinement parameters are listed in Table 1. An ORTEP type view of the asymmetric unit of $\mathrm{MBZH} \cdot \mathrm{SO}_{4} \mathrm{CH}_{3}$, displaying the atoms labelling and the $50 \%$ probability ellipsoids, is shown in Figure 2.B.

Protonation on $\mathbf{N} \mathbf{2}$ produces here the same effects on the bond lengths of the imidazole ring as described in the previous section. Imine and amine bonds are very similar: the bond between N2-C3 is 1.326(4) $\AA$, and the bond N3-C3 is 1.338(3) $\AA$. The displacement of the electron density also shortens the length of the bond linking imidazole ring to the carbamate moiety (N1-C3: 1.341(3) Å) (Figure S4). In this salt, the $\mathrm{MBZH}^{+}$ cation is found in a molecular conformation similar to the one adopted in the $\mathrm{MBZH} \cdot \mathrm{ClO}_{4}$ crystal structure. The benzimidazole ring is coplanar with the carbamate moiety, and the resonance-assisted intramolecular $\mathrm{H}$-bond between the imidazolic N3 and carbonylic $\mathbf{O 2}(\mathbf{A} \cdots \mathbf{H}: 2.21 \AA$, Table 2) is also present. The dihedral angle determined by the least-square planes through the benzimidazolic and the benzoyl rings is $54.32(14)^{\circ}$.

The crystal packing of the $\mathrm{MBZH} \cdot \mathrm{SO}_{4} \mathrm{CH}_{3}$ also shows the presence of infinite chains connected by the same intermolecular synthon with $\mathrm{R}_{2}{ }^{2}(8)$ motif, but in this case along the crystallographic $\boldsymbol{a}$ axis. These chains are stabilized by two

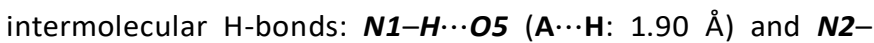
H...O4 (1.89 A) (Figure 4.C). This arrangement is almost planar: there is a dihedral angle of just $7.12(10)^{\circ}$ between the leastsquares planes through the N3, C3 and N1, and $04, S$ and 05 atoms. Each $\mathrm{MBZH}^{+} / \mathrm{SO}_{4} \mathrm{CH}_{3}{ }^{-}$pair is connected to the next ionic pair through two intermolecular H-bond: $\mathbf{N 3}-\boldsymbol{H} \cdots \mathbf{O} 7$ (2.04 $\AA$ ) and $\mathbf{C 1 7}-\boldsymbol{H} \cdots \mathbf{O 2}(2.53 \AA)$. These interactions form antiparallel chains in the [100] direction. Ionic pairs of adjacent chains are related again by an inversion center, giving rise to the formation of dimers.

In $\boldsymbol{b c}$ plane, antiparallel chains are connected by a short contact between $\mathbf{0 7}$ and $\mathbf{N 1}(2.988(3) \AA ̊)$ (Figure 4.A). This inter-chains contact connect the chains in a $A \cdots B \quad C \cdots D$ sequence, since all polarized groups are exposed between chains " $A$ " and " $B$ ", and " $C$ " and " $D$ ", awith methyl groups from methylsulfate anions laying between chains " $B$ " and " $C$ ". Two 
non-classical H-bonds are found between chains " $B$ " and " $C$ " in which one methylsulfate from chain " $C$ " acts both as acceptor $(\mathbf{O} 6 \cdots \boldsymbol{H}-\mathbf{C 7}, 2.55 \AA$ ) and donor $(\mathbf{C 1 7}-\mathbf{H} \cdots \mathbf{O}$. $2.68 \AA$ ) (Figure 4.B).

Adjacent chains are connected by two different contacts: one non-classical H-bond between 05 and $\mathrm{C13}(\mathrm{A} \cdots \mathrm{H}: 2.68 \AA$ ) , and one interaction between the bezoyilic 03 of one $\mathrm{MBZH}^{+}$ and $\boldsymbol{C} \mathbf{1}$ of next cation (3.213(4) $\AA$ ), forming infinite layers parallel to $\boldsymbol{a}$ axis (Figure $\mathbf{S 5}$ ).

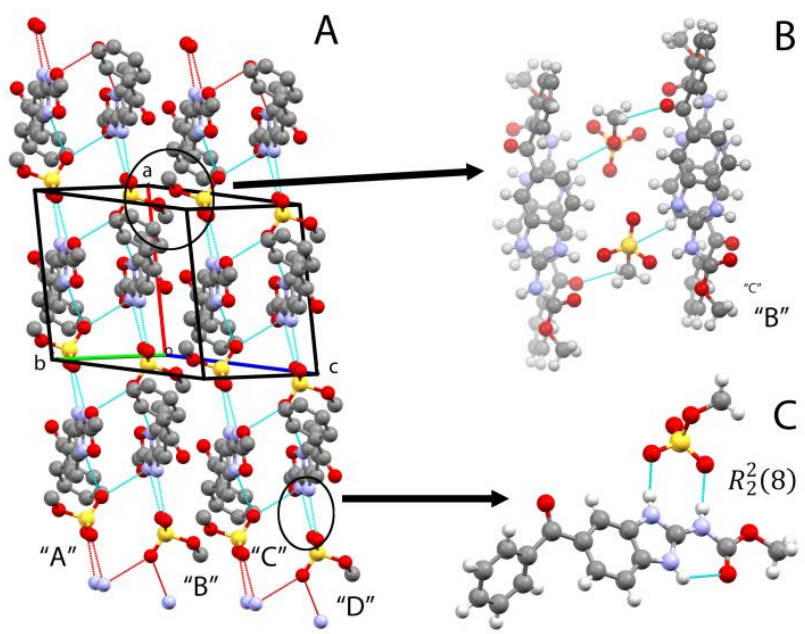

Figure 4.A. Antiparallel chains along $\boldsymbol{a}$ axis of ionic pairs $\mathrm{MBZH}^{+} / \mathrm{SO}_{4} \mathrm{CH}_{3}{ }^{-}$assembled by intermolecular $\mathrm{H}$-bonds.

B. Short-contact interactions $C-H \cdots O$ between " $B$ " and " $C$ " chains.

C. Supramolecular motif $\boldsymbol{R}_{\mathbf{2}}^{\mathbf{2}}(\mathbf{8})$ formed by one $\mathrm{MBZH}^{+}$cation and one $\mathrm{SO}_{4} \mathrm{CH}_{3}{ }^{-}$anion. (Color code. C: grey; $\mathrm{H}$ : white; O: red; $\mathrm{N}$ : blue; $\mathrm{S}$ : yellow.)

Hirshfeld surface analysis. Hirshfeld surface analysis shows that, as expected, the predominant intermolecular interactions are the $\mathrm{N}-\mathrm{H} \cdots \mathrm{O} \mathrm{H}$-bonds described in the previous sections, with the three $\mathrm{N}$ atoms of $\mathrm{MBZH}^{+}$acting as donors. These short $\mathrm{H}_{-}$ bonds are associated with two large red spots on the $d_{\text {norm }}$ [from -0.35 (blue) to $1.25 \AA$ (red)] mapped on the Hirshfeld surface of the cation (Figures 5A \& B).

However, the observation of the $d_{\text {norm }}$ surface of $\mathrm{MBZH}^{+}$ reveals that the $\mathbf{N 3}-\boldsymbol{H} \cdots \mathbf{O}$ 7 interaction is reinforced by an additional non-classical interaction $\mathbf{C 6}-\mathrm{H} \cdots \mathbf{O} 4(\mathrm{~A} \cdots \mathbf{H}: 2.68 \AA$ in $\mathrm{MBZH} \cdot \mathrm{ClO}_{4}$ and $2.62 \AA$ in $\mathrm{MBZH} \cdot \mathrm{SO}_{4} \mathrm{CH}_{3}$ ) (Figures 5C \& D). Furthermore, there is another non-classical interaction C17$\mathrm{H} \cdots \mathrm{O} 2\left(2.53 \AA\right.$ ) in $\mathrm{MBZH} \cdot \mathrm{SO}_{4} \mathrm{CH}_{3}$ in which the $\mathrm{MBZH}^{+}$cation acts as acceptor through the carbamic $O$. These longer contacts (and therefore weaker) are shown as faint red spots visible on the $d_{\text {norm }}$ surface (Figures 5D).

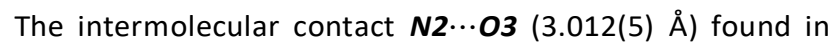
$\mathrm{MBZH} \cdot \mathrm{ClO}_{4}$ is reinforced by another short contact interaction between 03 and C3 (2.951(6) $\AA$ ) (Figure S6A). Both interactions are associated with a large red spot around $\mathbf{0 3}$ on the $d_{\text {norm }}$ surface. 2D-fingerprint plot reveals that this red spot presents an important contribution from this $\boldsymbol{C} \cdots \boldsymbol{O}$ contact (Figure S6B). The assembling of $\mathrm{MBZH}^{+}$cations in the ac plane is also stabilized by carbonyl $\cdots \pi$ interactions between the benzimidazole moiety of one $\mathrm{MBZH}^{+}$and the carbamate moiety of the next molecule, revealed by the pattern of red and blue triangles on the shape index surface (Figure S7A). Curvedness surface plots show flat patches above one side of the benzimidazole ring, and on the opposite side above the carbamate moiety, suggesting the same pattern of planar stacking of $\mathrm{MBZH}^{+}$molecules (Figure S7B). These interactions are absent in $\mathrm{MBZH} \cdot \mathrm{SO}_{4} \mathrm{CH}_{3}$ and the arrangement of infinite layers is only stabilized by discrete short-contact interactions.

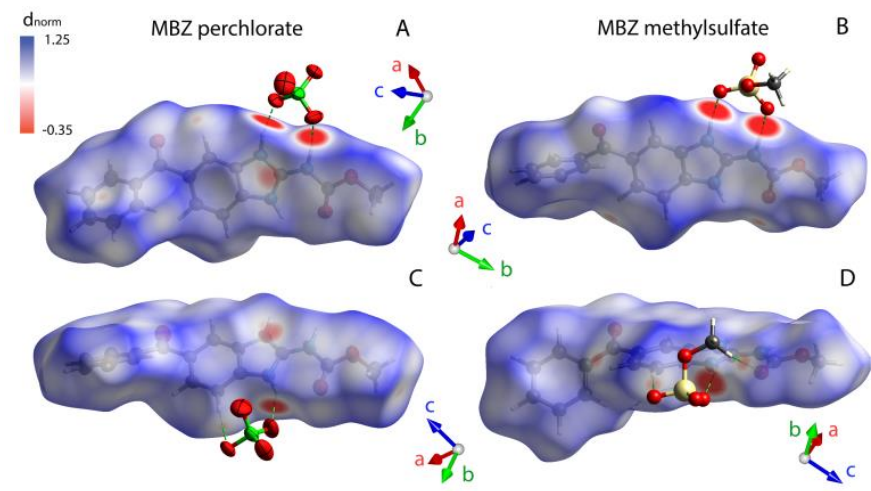

Figure 5. $\mathrm{MBZH}{ }^{+}$cations in $\mathrm{MBZH} \cdot \mathrm{ClO}_{4}(\mathbf{A} \& \mathbf{C})$ and $\mathrm{MBZH} \cdot \mathrm{SO}_{4} \mathrm{CH}_{3}(\mathbf{B}$ \& D) mapped with $d_{\text {norm }}$ surface.

\section{Thermal stability}

Thermal analysis revealed $\mathrm{MBZH} \cdot \mathrm{ClO}_{4}$ is stable up to 210 ${ }^{\circ} \mathrm{C}$. DTA and DSC curves show a first endothermic event (Temp. onset $210^{\circ} \mathrm{C}$, Temp. centered at $239^{\circ} \mathrm{C}$ ) associated with a relative mass loss of $14.77 \%$, as demonstrated by the TGA experiment, which is consistent with the mechanism proposed by Holanda et al. for MBZ degradation in air to form 2-amino5-benzoylbenzimidazole ${ }^{14}$. The loss of the methylester moiety in $\mathrm{MBZH}^{+}$cation implies a theoretical mass loss of $14.66 \%$. In order to obtain more evidence of this process, we conducted a temperature-variable FT-IR experiment. The progressive reduction of the intensity of the carbamate carbonyl band at $1759 \mathrm{~cm}^{-1}$ until it completely disappears, suggests that the same mechanism proposed by Holanda et al. operates in the first stage of $\mathrm{MBZH} \cdot \mathrm{ClO}_{4}$ degradation.

Thermal analysis curves and temperature-dependent vibrational spectra are shown in Figure 6 and Inset. This experiment shows an improvement in the drug thermal stability. In this way, this salt is even more stable than those salts and cocrystals previously reported (i.e.: MBZ mesylate monohydrate: $50{ }^{\circ} \mathrm{C}^{25}$, MBZ nitrate: $150{ }^{\circ} \mathrm{C}$, MBZ hydrochloride: $160{ }^{\circ} \mathrm{C}^{44}$ and MBZ/valeric acid cocrystal: 186 ${ }^{\circ} \mathrm{C}$ ). This stability could be attributed to the ability of the perchlorate anion to form a more stable supramolecular motif with the MBZ molecule, preventing the cleavage of the bond between the benzimidazole ring and the carbamate moiety at lower temperatures. 


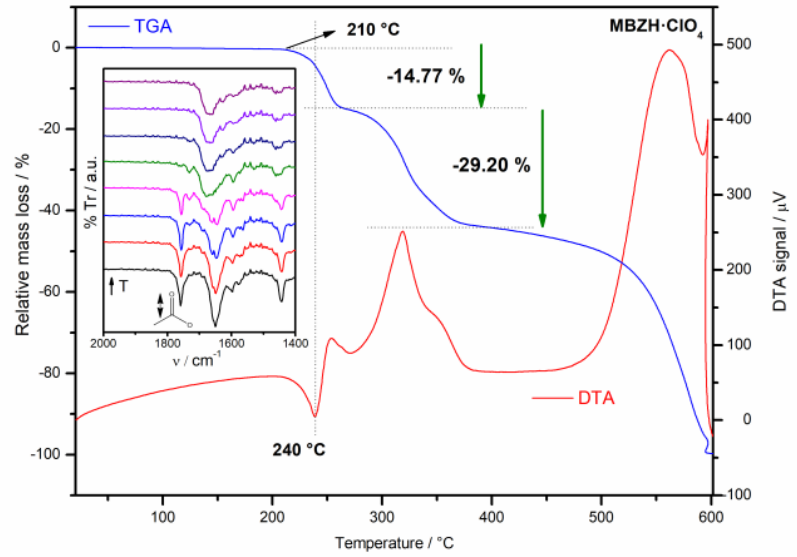

Figure 6. TGA and DTA curves of MBZ perchlorate. Inset: Temperaturevariable FT-IR spectra of MBZ perchlorate.

A second stage of the thermal decomposition starts almost immediately $\left(260{ }^{\circ} \mathrm{C}\right)$ and seems to involve two overlapped exothermic events with a relative mass loss of $29.00 \%$. Scheme S1 shows the propose decomposition mechanism in which the cleavage of the amine bond with the removal of ammonia is followed by the subsequent elimination of perchloric acid. Theoretical mass loss for these consecutives eliminations is $29.18 \%$, in good agreement with the experimental value. The final stage is the complete degradation of the remaining compound, 5-benzoylbenzimidazole.

$\mathrm{MBZH} \cdot \mathrm{SO}_{4} \mathrm{CH}_{3}$ is stable up to $160{ }^{\circ} \mathrm{C}$, when begins a relative mass loss of $19.77 \%$ (corrected: $17.98 \%$ ) associated with an endothermic signal in the DTA curve (centered at $180{ }^{\circ} \mathrm{C}$ ) consistent with the cleavage of the amine bond and the elimination of the entire methylcarbamate moiety (theoretical mass loss: $17.94 \%)$. Since the end of this event in TGA and DTA was not clear, we made use of the first derivate to identify it. The removal of methylsulfuric acid and the final degradation of the organic product seem to be overlapped and there is no defined temperature when these processes begin. Thermal analysis curves are shown in Figures 59. The laminar disposition of the ions in the crystal structure may be the cause of this lesser stability. The presence of the methyl groups of methylsulfate anions pointing towards the interior of chains " $B$ " and " $C$ " keep layers apart and reduce the ability of the anions to interact with the MBZ molecules, preventing a better stabilization of the crystal structure and reducing the thermal stability of the compound.

Differences in stability could also be understood in terms of the different patterns of intermolecular interactions revealed by Hirshfeld surface analysis. In both salts, $\mathrm{N}-\mathrm{H} \cdots \mathrm{O} \mathrm{H}$-bonds are predominant; however these interactions represent a greater percentage of the $d_{\text {norm }}$ surface in $\mathrm{MBZH} \cdot \mathrm{ClO}_{4}$. Also, an important percentage of $\mathrm{MBZH} \cdot \mathrm{SO}_{4} \mathrm{CH}_{3} \quad d_{\text {norm }}$ surface is associated with $\mathrm{H} \cdots \mathrm{H}$ contacts. In addition to that, the planar stacking arrangement of $\mathrm{MBZH}^{+}$in $\mathrm{MBZH} \cdot \mathrm{ClO}_{4}$ is stabilized by two short contact interactions (with $d_{\text {norm }}$ shorter than the sum of the van der Waals radii) and others $C \cdots C(\pi \cdots C)$ interactions, while in $\mathrm{MBZH} \cdot \mathrm{SO}_{4} \mathrm{CH}_{3}$ the infinite layers are only stabilized by discrete short contacts, with $d_{\text {norm }}$ greater than the sum of the van der Waals radii. Scheme $\mathbf{S 1}$ shows the propose decomposition mechanisms for both salts.

$\mathrm{MBZH} \cdot \mathrm{ClO}_{4}$ appears to be the most stable solid form of the API reported to date, while the stability of $\mathrm{MBZH} \cdot \mathrm{SO}_{4} \mathrm{CH}_{3}$ is similar to that of $\mathrm{MBZ} /$ butyric acid cocrystal $\left(163.5{ }^{\circ} \mathrm{C}\right.$ ) previously reported by Chen et al. (2013) $)^{28}$.

\section{Solubility and stability in solution and in water suspension}

Using the shake flask saturation method (USP) we determine an improvement in a factor of 7 in the apparent equilibrium solubility of $\mathrm{MBZH} \cdot \mathrm{ClO}_{4}$ respect to $\mathrm{MBZ} A$, in 0.1 mol L ${ }^{-1}$ hydrochloric acid solution. However, this experiment is not suitable for the determination of the equilibrium solubility of the API. This method is based on the assumption that the solid product does not undergo phase transitions or any other transformation during the experiment. This apparent solubility increase could be considered a drawback since it is similar to that of MBZ B which is toxic. Nevertheless, this increment is lesser than those previously reported for some MBZ salts and cocrystals also obtained by crystal engineering techniques ${ }^{27}$.

MBZ salts reported here are metastable forms of the drug in the conditions of the equilibrium solubility experiment, and the transformation to a more stable phase occurs. After 48 hours in contact with the solvent, samples of $\mathrm{MBZH} \cdot \mathrm{ClO}_{4}$ salt suffered a transformation process. As shown in Figure S10, the comparison of powder X-ray diffraction patterns of those samples, before and after the experiment, with those of $\mathrm{MBZ}$ polymorphs, shows that $\mathrm{MBZH} \cdot \mathrm{ClO}_{4}$ transforms into $\mathrm{MBZ} A$ while previous reports indicate that other $M B Z$ salts transforms into MBZ $C$ in similar conditions ${ }^{29,30}$. This transformation can be justified by the great difference in solubility of the two components of the salt: the perchlorate anions completely dissolve in the solution, while the MBZ molecules precipitate to form the polymorph $A$. In order to determine a more representative value of the solubility of these salts, we designed a modified method that takes into account the kinetics of the process, both in the solution and in the solid phase, which we will apply to study the dissolution behaviour of several MBZ salts ${ }^{30}$.

Once dissolved, MBZ exhibits a behaviour that is independent of its solid form. MBZ methanolic solution shows three bands in the UV region: $212 \mathrm{~nm}, 247 \mathrm{~nm}$ and $311 \mathrm{~nm}$. In ultrapure water ( $\mathrm{pH} \mathrm{7)}$, these bands are at $209 \mathrm{~nm}, 249$, and $313 \mathrm{~nm}$. The little effect of the solvent polarity on the position of these bands suggests an important hydrophobicity and poor solvation in polar media. The spectrum of MBZ shows a hypsochromic effect in $0.1 \mathrm{~mol} \mathrm{~L}^{-1}$ hydrochloric acid solution. The bands shift to lower wavelength (201, 233, and $287 \mathrm{~nm}$ ) since the absorbent species in this medium is the cation $\mathrm{MBZH}+(\mathrm{MBZ}$ is completely protonated at $\mathrm{pH} \cong 1$ ). The anion MBZ $(-H)^{-}$prevails at $\mathrm{pH} \geq 10^{35}$, and the excess of negative charge on the benzimidazole ring shifts the spectrum towards higher wavelengths (Figure 7.A).

Regarding its stability in solution, MBZ is extremely stable in methanol and in $0.1 \mathrm{~mol} \mathrm{~L}^{-1}$ hydrochloric acid solutions. The 
spectra of MBZ solutions fresh and after several days of prepared (kept at $25^{\circ} \mathrm{C}$ ) show little changes in the intensities of the bands, attributed to the precipitation of the drug (Figure 7.B). On the other hand, MBZ undergoes a fast degradation process in water solutions when the $\mathrm{pH}$ of the medium is increased (Figures 7.C and 7.D). This is in good agreement with the hydrolysis of carbamates extensively reported ${ }^{49,50}$.
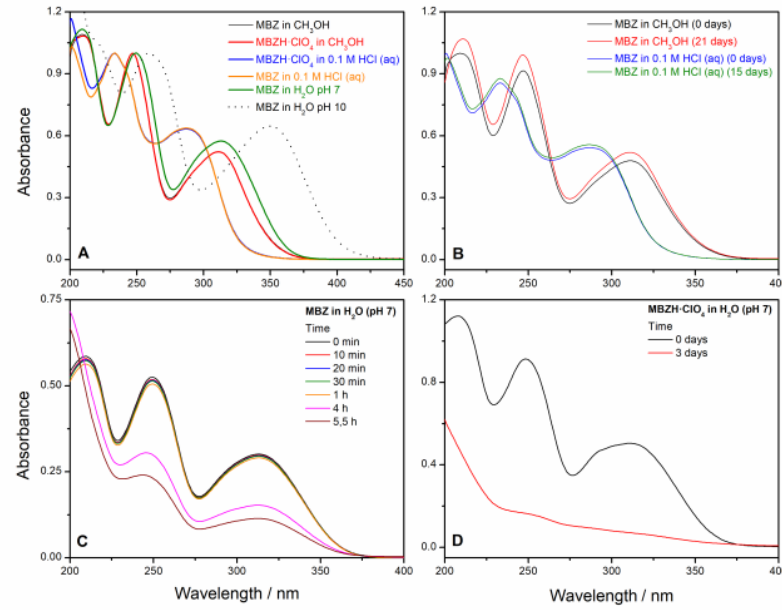

Figure 7.A. Mebendazole UV-visible spectra in water and methanol. B. Stability of mebendazole in methanol and $0.1 \mathrm{~mol} \mathrm{~L}^{-1}$ hydrochloric acid aqueous solution. C. Degradation of $\mathrm{MBZ}$ in water $\mathrm{pH} 7$. D. Degradation of $\mathrm{MBZH} \cdot \mathrm{ClO} 4$ in water $\mathrm{pH} 7$.

\section{Conclusions}

Two novel mebendazole (MBZ) bicomponent systems were developed and characterized in solid state and in solution. Recrystallization of MBZ with perchloric and methylsulfuric acids by slow solvent evaporation yielded two ionic solids forms of $1: 1$ stoichiometry: $M B Z$ perchlorate $\left(P 2_{1} / n\right)$ and $M B Z$ methylsulfate $(P-1)$. As expected, both anions form a supramolecular motif of the $\mathrm{R}_{2}{ }^{2}(8)$ type through the formation of two intermolecular $\mathrm{N}-\mathrm{H} \cdots \mathrm{O} \mathrm{H}$-bonds. Ionic pairs are found in dimers related by an inversion center assembled in antiparallel chains by intermolecular $\mathrm{H}$-bonds, acting the anions as bridges between MBZ molecules. Several other important $\mathrm{H}$-bonds and short-contact interactions stabilized the crystal packings. Hirshfeld surface analysis revealed that the predominant intermolecular interactions are the $\mathrm{N}-\mathrm{H} \cdots \mathrm{O}$ $\mathrm{H}$-bonds where the three $\mathrm{N}$ atoms of $\mathrm{MBZH}^{+}$acts as donors. MBZ perchlorate is stable up to $210{ }^{\circ} \mathrm{C}$, when occurs the endothermic elimination of the methylester moiety of the drug. We found an improvement in the thermal stability of the drug, since this salt is more stable than MBZ polymorph and other multicomponent systems previously reported. On the other hand, MBZ methylsulfate first degradation step begins at $160{ }^{\circ} \mathrm{C}$ and follows a different mechanism. These formulations avoided polymorph conversion and showed good stability in the solid state when they were stored at room temperature. Preliminary experiments showed an improvement in MBZ perchlorate with respect to MBZ in a factor of 7 . However further experiments are needed to study the kinetics aspects of both the dissolution process of these salts and the stability of the drug in aqueous media.

\section{Conflicts of interest}

There are no conflicts to declare.

\section{Acknowledgements}

This work was supported by Universidad Nacional de San Luis (PROICO 02-3218 and PROICO 02-2016), and Consejo Nacional de Investigaciones Científicas y Técnicas (CONICET), all in Argentina. The authors also acknowledge Farm. Elbio Saidman from Laboratorio de Control de Calidad de Medicamentos (UNSL) for kindly supplying the MBZ A and C samples. Authors are grateful for the financial support provided by CNPq (JE Proc. \# 305190/2017-2).

\section{Notes and references}

1 P. Nygren, M. Fryknäs, B. Ågerup and R. Larsson, J. Cancer Res. Clin. Oncol., 2013, 139, 2133-2140.

2 H. V. Chavda, C. N. Patel and I. S. Anand, Sys Rev Pharm, 2010, 1, 62-69.

3 J. Costa, M. Fresno, L. Guzmán, A. Igual, J. Oliva, P. Vidal, A. Pérez and M. Pujol, Circ. Farm. - Barcelona, 1991, 49, 415424.

4 World Health Organization, WHO 19th Model List of Essential Medicines (April 2015) (Amended November 2015), http://www.who.int/medicines/publications/essentialmedici nes/en/

5 A. C. Evans, J. E. Fincham, M. A. Dhansay and W. Liebenberg, South African Med. J., 1999, 89, 1118.

6 E. Swanepoel, W. Liebenberg, B. Devarakonda and M. M. De Villiers, Pharmazie, 2003, 58, 117-121.

7 E. Swanepoel, W. Liebenberg and M. M. De Villiers, Eur. J. Pharm. Biopharm., 2003, 55, 345-349.

8 S. Agatonovic-Kustrin, B. D. Glass, M. Mangan and J. Smithson, Int. J. Pharm., 2008, 361, 245-250.

9 W. Liebenberg, T. G. Dekker, A. P. Lötter and M. M. de Villiers, Drug Dev. Ind. Pharm., 1998, 24, 485-488.

10 Y. Kasetti and P. V. Bharatam, Theor. Chem. Acc., 2012, 131, 1-12.

11 F. F. Ferreira, S. Antonio Gutierrez, P. C. Pires Rosa and C. de O. Paiva-Santos, Int. J. Drug Dev. Res., 2011, 3, 26-33.

12 F. T. Martins, P. P. Neves, J. Ellena, G. E. Camí, E. V. Brusau and G. E. Narda, J. Pharm. Sci., 2009, 98, 2336-2344.

13 M. M. De Villiers, R. J. Terblanche, W. Liebenberg, E. Swanepoel, T. G. Dekker and M. Song, J. Pharm. Biomed. Anal., 2005, 38, 435-441.

14 B. B. C. Holanda, R. T. Alarcon, R. B. Guerra, D. Rinaldo, F. C. R. Spazzini, R. A. E. Castro and G. Bannach, J. Anal. Appl. Pyrolysis, 2018, 135, 76-84.

15 R. L. Roque-Flores, J. F. de Oliveira, F. M. de S. Carvalho and J. do R. Matos, J. Pharm. Innov., 2020, 15, 116-124.

16 P. Charoenlarp, J. Waikagul, C. Muennoo, S. Srinophakun and D. Kitayaporn, Southeast Asian J. Trop. Med. Public Health, 1993, 24, 712-716.

17 N. L. Calvo, T. S. Kaufman and R. M. Maggio, J. Pharm Biomed. Anal., 2016, 122, 157-165.

18 D. J. Berry and J. W. Steed, Adv. Drug Deliv. Rev., 2017, 117 3-24. 
19 J. Wounters and L. Quéré, Phamaceutical Salts and Cocrystals, RSC Publishing, Cambridge, 2012.

20 Food and Drug Administration (FDA), U.S. Department of Health and Human Services, Approved Drug Product with Therapeutic Equivalence Evaluations $40^{\text {th }}$ Edition ("Orange Book") (2020), http://www.fda.gov/drugs/drug-approvalsand-databases/approved-drug-products-therapeuticequivalence-evaluations-orange-book

21 Y. Ma, S. Ge, W. Wang, Q. Zheng, Y. Zuo, C. Zhong and B. Sun, J. Mol. Struct., 2016, 1105, 1-10.

22 P. Deepa, R. Vijay Solomon, S. Angeline Vedha, P. Kolandaivel and P. Venuvanalingam, Mol. Phys., 2014, 112, 3195-3205.

23 N. M. Blaton, O. M. Peeters and C. Deranter, Cryst. Struct. Commun., 1980, 9(1), 181-186.

24 E. V. Brusau, G. E. Camí, G. E. Narda, S. Cuffini, A. P. Ayala and J. Ellena, J. Pharm. Sci., 2008, 97, 542-552.

25 K. de Paula, G. E. Camí, E. V. Brusau, G. E. Narda and J. Ellena, J. Pharm. Sci., 2013, 102, 3528-3538.

26 M. Caira, T. Dekker and W. Liebenberg, J. Chem. Crystallogr., 1998, 28, 11-15.

27 J.-M. Chen, Z.-Z. Wang, C.-B. Wu, S. Li and T.-B. Lu, CrystEngComm, 2012, 14, 635-640.

28 J. Chen and T. Lu, Chinese J. Chem., 2013, 31, 635-640.

29 E. L. Gutiérrez, M. S. Souza, L. F. Diniz and J. Ellena, J. Mol. Struct., 2018, 1161, 113-121.

30 G. E. Camí, E. V. Brusaua, G. E. Narda and R. M. Maggio, J. Drug Deliv. Sci. Technol., 2020, 15, 101344.

31 J. J. McKinnon, M. A. Spackman and A. S. Mitchell, Acta Crystallogr. Sect. B, 2004, B60, 627-668.

32 M. A. Spackman and D. Jayatilaka, CrystEngComm, 2009, 11, 19-32.

33 E. C. Minerath, M. T. Casale and M. J. Elrod, Environ. Sci. Technol., 2008, 42, 4410-4415.

34 C. P. Mumma and R. O. Hoiberg, J. Am. Chem. Soc., 1969, 91, 4273-4278.

35 H. Wan, A. G. Holmén, Y. Wang, W. Lindberg, M. Englund, M. B. Någård and R. A. Thompson, Rapid Commun. Mass Spectrom., 2003, 17, 2639-2648.

36 SAINT, Version 7.60a, Bruker AXS Inc, Madison, WI, USA 2006.

37 Bruker AXS I. APEX2 Version 2.1-0, 2004.

38 G. M. Sheldrick, Acta Crystallogr. Sect. A, 2015, A71, 3-8.

39 O. V. Dolomanov, L. J. Bourhis, R. J. Gildea, J. A. K. Howard and H. Puschmann, J. Appl. Crystallogr., 2009, 42, 339-341.

40 F. H. Allen, Acta Crystallogr. Sect. B Struct. Sci., 2002, 58, 380-388.

41 C. F. Macrae, P. R. Edgington, P. McCabe, E. Pidcock, G. P. Shields, R. Taylor, M. Towler and J. van de Streek, J. Appl. Crystallogr., 2006, 39, 453-457.

42 A. L. Spek, J. Appl. Crystallogr., 2003, 36, 7-13.

43 Louis J. Farrugia, J. Appl. Crystallogr., 2012, 45, 849-854.

44 S. K. Wolff, D. J. Grimwood, J. J. McKinnon, D. Jayatilaka and M. A. Spackman, 2017.

45 United States Pharmacopeia and National Formulary USP 29NF 24, 2006.

46 A. P. Ayala, H. W. Siesler and S. L. Cuffini, J. Raman Spectrosc., 2008, 39, 1150-1157.

47 M. Karashima, K. Kimoto, T. Kojima and Y. Ikeda, J. Cryst. Growth, 2014, 390, 30-37.

48 G. Gilli, F. Bellucci, V. Ferretti and V. Bertolasi, J. Am. Chem. Soc., 1989, 111, 1023-1028.

49 L. W. Dittert and T. Higuchi, J. Pharm. Sci., 1963, 52, 852857.
50 F. P. Norberto, S. P. Santos, J. lley, D. B. Silva and M. Corte Real, J. Braz. Chem. Soc., 2007, DOI: 10.1590/S010350532007000100019 